\title{
The Importance of Globalization in Higher Education
}

\author{
Patricia Fox and Stephen Hundley \\ Indiana University Purdue University Indianapolis \\ United States of America
}

\section{Introduction}

Globalization is about the interconnectedness of people and businesses across the world that eventually leads to global cultural, political and economic integration. It is the ability to move and communicate easily with others all over the world in order to conduct business internationally. The word, globalization, is relatively new, coined in the late 1970's. The airplane, the telephone, and the Internet are just three inventions, which are attributable to the spread of globalization. Due to the increased demand in the high tech industry around the world, business and industry have potential for huge profits working globally. So in today's world, globalization is an important concept for students in higher education to understand and appreciate because of the demand in business and industry to hire people who can work with people of other nations and cultures and if need be can travel independently internationally to promote their business or industry. In addition, the world faces global challenges that will take interdisciplinary groups to solve these challenges; providing access to clean water for everyone on this planet and making clean renewable energy affordable just to name a few. These global challenges will need to be solved through the gathering and sharing of knowledge across disciplines, institutions, and other entities institutions on a global scale. Creating meaningful relationships that work globally is in itself challenging. In this chapter, we will look at global challenges, the makeup of model collaborative international teams; the importance of teaching globalization in higher education, how to best teach globalization, and discuss best practices in this area.

\section{Recent history of globalization}

How did our world become so global? In a book titled, The World is Flat, Thomas Friedman describes ten forces in the world that flattened the world and made it global. Those ten flatteners of the world include:

- 11/9/89 -The New Age of Creativity: When the Walls Came Down and the Windows Went Up

- 8/9/95 The New Age of Connectivity: When the Web Went Around and Netscape Went Public

- Work Flow Software

- Uploading: Harnessing the Power of Communities

- $\quad$ Outsourcing and $\mathrm{Y} 2 \mathrm{~K}$ 
- Offshoring: Running with Gazelles, Eating with Lions

- Supply Chaining --Eating Sushi in Arkansas

- Insourcing --What the Guys in the Funny Brown Shorts Are Really Doing

- In-Forming --Google, Yahoo, MSN Web Search

- The Steroids - Digital, Mobile, Personal and Virtual.

The first force to flatten the world was on 11/9/89, the fall of the Berlin Wall. Freidman calls this, The New Age of Creativity: When the Walls Came Down and the Windows Went Up. While the fall of the Wall liberated the Soviet citizens, it changed the balance of power towards democratic, free market government from authoritarian rule with central planned economies. In addition, there were ripple effects felt all over the world from the fall of the Wall one of those places was India. In 1991, India abolished trade controls after years of being almost bankrupt and then it started to prosper and grow all because of the fall of the Wall. Around the same time, May 22, 1990, IBM shipped Windows 3.0, a breakthrough version that made PCs easier to use. This version allowed millions of people for the first time to be authors of their own content in digital form, and share their content with others. As the Berlin Wall went down, Window went up. Freidman say, "The fall of the Berlin Wall didn't just help flatten the alternatives to free-market capitalism and unlock enormous pent-up energies for hundreds of millions of people in places like India, Brazil, China, and former Soviet Empire. It allowed us to think about the world differently - to see it as more of a seamless whole. Because the Berlin Wall was not only blocking our way; it was blocking our sight-our ability to think about the world differently - to see it more as a seamless whole" (Freidman, 2007, pg. 54).

The second flattener of the world according to Freidman was 8/9/95 The New Age of Connectivity: When the Web Went Around and Netscape Went Public. The Internet was developed by Tim Berners-Lee in 1991, a British Computer Scientist. However, the Internet alone was not enough to manage the second flattening. The Internet coupled with Netscape, which went public in 1995, was the second flattener. Netscape made the Internet accessible to almost everyone. Fifteen days after Netscape was released, Windows 95 was released as the first operating system with a built-in Internet support system (Freidman, 2007).

The third world flattener was Work Flow Software as demonstrated by a company named Wild Brain, which makes animated movies. This company has been taking advantage of the flattened world by making animated films through a global supply chain. To see how this works, look at an example of one show called, Higglytown Heroes. The recording for the show is done in New York city or Los Angeles, California. The design and direction for the show is done in San Francisco, California. The writers network with each other from Florida, London, New York, Chicago, Los Angeles, and San Francisco. While the animation characters are done in Bangalore, India with edits in San Francisco, California. All of these groups work together on a virtual private network (VPN) system. Freidman said, "When the walls went down, and then the PC and Netscape browser enabled people to connect with other people as never before, it did not take long before all these people who were connecting wanted to do more than just browse and send email, instant messages, pictures and music over this Internet platform. They wanted to shape things, design things, create things, sell things, buy things, keep track of inventories, do somebody else's taxes, and read somebody else's X-rays from half a world away (2007, pg 79.). Everything to do with computers and the Internet has transformed our lives as they are today. What is also important to note is we have evolved to where different types of computers can talk to each other over the Internet using standardized protocols that have been developed. What a drastic change from when the first personal computer went public in 1981. 
Uploading: Harnessing the Power of Communities was Freidman's fourth world flattener. Apache is an open-source web tool that allows a single server machine to host thousands of different virtual websites-music, data, text or anything. Apache proved to be an excellent product that was developed by a group of computer geeks who gave it away for free. IBM couldn't design anything better so it decided to join the group. IBM made a deal to help form a legal structure for Apache so there would be no copyright issues in using other products developed to be used with Apache. IBM's buy-in also indicated to the computer community that this new way of building software that was trustworthy and valuable. In another example, a 19 year old from Stanford and a 24 year old from New Zealand developed Firefox 1.0 as an open-source community software for free in 2004 (Freidman, 2007). Freidman said, “.... the reason, I think community-developed software is also here to stay is that while it may not be sustainable without an economic incentive at some point, as a sheer tool for making breakthroughs and spreading those breakthroughs virally, it has proved to be very powerful" (2007, pg.111).

Freidman's fifth world flatteners are Outsourcing and Y2K. By the late 1990's, good things started happening in India; first the fiber optic cable linking India and the United States was exploding and the $\mathrm{Y} 2 \mathrm{~K}$ was on the horizon for January 1, 2000. The $\mathrm{Y} 2 \mathrm{~K}$ centered on a bug in computers and their internal clocks. When computers were first built to save memory space, internal clocks had two digits for the month, two digits for the day, and two digits for the year. So the issue with Y2K was that these internal clocks would mess up the entire computer because it could not go forward to the year 2000. America and India started having a relationship in a sense that started the huge flattener because with the fiber optic cable and the Internet this created a collaborative value added sources, so that businesses could source globally to the cheapest and smartest location, thus the relationship between India and America strengthened. The Y2K computer problem was fixed by low cost Indian labor and thus also a relationship between American business and Indian IT companies had been established. Therefore, the cheaper very good Indian IT companies prospered from these two events, the fiber optic networks and Y2K. Freidman said, " ...I believe that Y2K should be a national holiday in India, a second Indian Independence Day, in addition to August 15. .... because it was India's ability to collaborate with Western companies, thanks to the interdependence created by fiber-optic networks, that really vaulted it forward and gave more Indians than ever some real freedom of choice in how, for whom and where they worked"' (2007, pg.136).

Freidman's sixth flattener of the world was Offshoring: Running with Gazelles, Eating with Lions. China joined the World Trade Organization (WTO) on December 11, 2001. They agreed to follow the same global rules governing imports, exports and foreign investments that other WTO countries in the world were following. This opened China up for a huge influx of companies working inside of China. Offshoring is when a company takes a whole factory and relocates it to another country (offshore). An example of offshoring is when, a whole factory moves from Fargo, North Dakota to Canton, China where it would produce the exact same product in the same way only much cheaper. Outsourcing is unlike offshoring, which is taking just one part of a business; for example, accounts receivable and having another company perform the exact same functions for a much cheaper cost, which the original company was doing in-house and reintegrating their work back into the original company's operation. By China joining the WTO, China ultimately became a challenge to the whole world with its mass of low-wage unskilled and semi-skilled workers. Other poor countries like Malaysia, Thailand, Ireland, Mexico, Brazil and Vietnam have to compete for 
better tax breaks, subsidies, and other factors to encourage offshoring to their shores. Another problem that exists is workplace standards, lax labor laws, and low wages just to name a few. In talking about offshoring, Freidman tells a story about a friend of his who is an American-trained Chinese manager of a fuel pump factory in Beijing. Shortly after China joined the WTO, his friend posted the following proverb from Africa translated into Mandarin on the factory floor:

Every morning in Africa, a gazelle wakes up.

It knows it must run faster than the fastest lion or it will be killed.

Every morning a lion wakes up.

It knows it must outrun the slowest gazelle or it will starve to death.

It doesn't matter whether you are a lion or a gazelle.

When the sun comes up, you better start running (Freidman, 2007).

Friedman concludes by saying, ".... if Americans and Europeans want to benefit from the flattening of the world and the interconnecting of all the markets and knowledge centers, they will all have to run at least as fast as the fastest lion-and I suspect that lion will be China, and I suspect that will be pretty darn fast" (2007, pgs.150-151).

Freidman's seventh flattener was Supply-Chaining - Eating Sushi in Arkansas. Wal-Mart is undoubtedly the largest retail company in the world and it does not manufacture a single product it sells. At Wal-Mart's headquarters in Bentonville, Arkansas they have a 1.2 million square foot distribution center that has a sophisticated global supply chain. This supply chain moves 2.3 million general merchandise cartons a year down its supply chain and into its stores. As one box gets transported through the supply chain, the engineering system keeps track of it coming in, where it is needed, if it needs to be supplied again, and if it does it sends the order in all automatically. Supply chaining allows suppliers, retailers, and customers to create value by collaborating horizontally. Supply chaining also forces common standards between companies so that every process can interface with the next. These types of global supply chains have become important all over the world, the challenges are global optimization and coordination disruption prone supply with hard to predict demand. Wal-Mart is very good at redirecting its products when there is a change in demand. If demand is low in Texas then products can be redirected midstream to Indiana. What does sushi in Arkansas have to do with supply chaining? With its role as one of the ten forces that flattened the world, Wal-Mart in Bentonville, Arkansas was one of those places Thomas Friedman needed to see for himself. Freidman said, "I was thinking, Boy I would really like some sushi tonight. But where am I going to find sushi in northwest Arkansas? And even if I found it, would I want to eat it? Could you really trust eel in Arkansas? When I arrived at the Hilton near Wal-Mart's headquarters, I was stunned to see, like a mirage, a huge Japanese steak house-sushi restaurant right next door (2007, pg156). As it turned out there were three new Japanese restaurants opening soon in Bentonville. The demand for sushi in Arkansas was not an accident, it had to do with the fact that all of the suppliers of Wal-Mart had also opened up shop in Bentonville, which is now referred to as "Vendorville" (Freidman, 2007).

Freidman's eighth flattener was Insourcing- What the Guys in Funny Brown Short Are Really Doing. It seems that UPS and FedEx both are synchronizing global supply chains for small and large companies. UPS headquarters is located in Atlanta but the UPS Worldport distributions hub is located next to the Louisville International Airport, which at night is taken over by the UPS fleet of cargo jets (270 aircraft) as packages are flown all over the world, sorted, and flown back out again a few hours later. However, UPS is much more 
than just a delivery company of packages. It does much more, for example, when you send your Toshiba laptop to be fixed via UPS what actually happens is that UPS is fixing the computers at its hub in Louisville in a special clean room where UPS employees are wearing blue smocks and replacing broken motherboards in Toshiba computers and shipping them out again. They are doing the same kinds of services for other companies like Papa John's Pizza. UPS employees are driving Papa John's Pizza trucks delivering supplies to various stores. UPS does work for Nike, Jockey and HP by having warehouses of products where they can fill the orders and the orders can be shipped via UPS. This type of business started around 1996, when UPS created a whole new global business opportunity. The term "Insourcing" fits the best for this work because UPS engineers go inside a business, analyze its manufacturing, packaging, and delivery processes; and then designs, redesigns, and manages the whole global supply chain. If a company needs it, UPS will finance part of the business. Freidman says, "UPS is creating enabling platforms for anyone to take his or her business global or to vastly improve the efficiency of his or her global supply chain" (2007, pg 175).

The ninth flattener was In-Forming- Google, Yahoo, MSN Web Search. According to Freidman, In-Forming is the individual or personal analog to uploading, outsourcing, insourcing, supply-chaining, and offshoring (2007). Whether it is Google, Yahoo, or MSN Web Search, when these search engines were new, people would react with eureka moments when they found the something in a search that was really good. Now people presume they will find the data they are looking for when they are doing a search. It is staggering the amount of information that is out to be mined. In-forming also involves searching for friends, allies, and collaborators. Search engines are businesses too. Freidman said, "Everyone can now be Googled-but everyone now can also Google. Google also equalizes access to information - it has no class boundaries, few education boundaries, few linguistic boundaries, and virtually no money boundaries" (2007, pgs.184-185).

The tenth and final flattener of the world was The Steroids- Digital, Mobile, Personal, and Virtual. In this flattener there are six steroids. The first steroid has to do with computing and the computational capacities, storage capacity, and input/output capacity of computers. In 1971, the Intel 404 processor produced only 60,000 instructions per seconds. Today's processor does over 20 billion instructions per second. Not only are the chips faster they are also smaller. The second steroid is the breakthroughs in instant messaging and file sharing. The third steroid is the ability to make phone calls over the Internet. The fourth steroid is videoconferencing. The fifth steroid is the advances in computer graphics driven by computer games. The sixth steroid is the most impressive; it's the wireless technology and all the devices. Freidman said, "As a result of these steroids, engines can now talk to computers, people can talk to computers, and people can talk to computers farther, faster, more cheaply, and more easily than ever before. And as that has happened, more people from more places have started asking one another the same two questions: Can you hear me now? Can we work together now?"(2007, pg. 198-199).

\section{Global challenges}

Over the last century, amazing inventions and innovations have transformed many lives around the world, they include: the airplane; automobile; radio and television; electrification; water supply and distribution; electronics; telephony; air condition and refrigeration; highways; spacecrafts; computers; Internet; imaging; household appliances; 
health technologies; petroleum and petroleum technologies; laser and fiber optics; nuclear technologies; and high performance materials (Constable \& Somerville, 2003). None of these inventions would have been possible without mathematicians, scientists, engineers, and technologists working together. The world needs all of these professions to collaborate globally on global challenges and create the inventions that will make our lives better in the $21^{\text {st }}$ century.

Many groups have weighed in on the global challenges Scientist, Engineers, Futurist, etc. Scientist in the InterAcademy Panel, a global network of the world's science academies, a group of 70 scientist from various academies around the world, were recently polled at a conference hosted by the Royal Society in London, they listed the following in order as the global challenges for the world in 2020:

1. Climate Change

2. Food Security

3. Loss of Biodiversity

4. Water Shortages

5. Global Population

6. Education

7. Nuclear Issues

8. Pandemics

9. Ageing

10. Poverty

11. Terrorism (Highfield \& Lawton, 2010).

Engineers in the United States (U.S.) through a panel convened by the U. S. National Academy of Engineering (NAE) on the other hand have another list of Global Challenges. These are their challenges:

1. Make solar energy economical

2. Provide energy from fusion

3. Develop carbon sequestration methods

4. Manage the nitrogen cycle

5. Provide access to clean water

6. Restore and improve urban infrastructure

7. Advance health informatics

8. Engineer better medicines

9. Reverse-engineer the brain

10. Prevent nuclear terror

11. Secure cyberspace

12. Enhance virtual reality

13. Advance personalized learning

14. Engineer the tools of scientific discovery (Grand Challenges for Engineering Committee, 2008).

The Millennium Project, which is a global think tank, founded in 1996. This think tank connects international experts in universities, corporations, NGOs, UN agencies and governments all around the world. The Millennium project has list of 15 Global Challenges. Their Global Challenges, which are more extensive than the other groups, are as follows:

1. How can sustainable development be achieved for all while addressing global climate change? 
2. How can everyone have sufficient clean water without conflict?

3. How can population growth and resources be brought into balance?

4. How can genuine democracy emerge from authorization regimes?

5. How can policymaking be made more sensitive to global long-term perspectives?

6. How can the global convergence of information and communication technologies work for everyone?

7. How can ethical market economies be encouraged to help reduce the gap between rich and poor?

8. How can the threat of new and reemerging diseases and immune micro-organisms be reduced?

9. How can the capacity to decide be improved as the nature of work and institutions change?

10. How can shared values and new security strategies reduce ethnic conflicts, terrorism, and the use of weapons of mass destruction?

11. How can the changing status of women help improve the human condition?

12. How can transnational organized crime networks be stopped from becoming more powerful and sophisticated global enterprises?

13. How can growing energy demands be met safely and effectively?

14. How can scientific and technological breakthrough be accelerated to improve the human condition?

15. How can ethical considerations become more routinely incorporated into global decisions? (Glenn, Gordon \& Florescu, 2010)

If you look at all three of these global challenging lists, many of them are similar which tells us that these truly are important global challenges and they have been thought out by a number of different groups. The question is how do we solve these challenges? That is the billion dollar question.

One way to solve global challenges would be for mathematicians, scientists, engineers, and technologist all over the world to work on these global challenges together, some of that is happening now, but not to the extent that it could or should be happening. Unfortunately, in the U.S. higher education institutions are focused on becoming the best research institutions. The university's traditional rewards for faculty engaged in research are for individual accomplishments. While lip service is given to rewarding faculty who collaborate in research, collaborating doesn't get a faculty member promoted or tenured at research universities. There has been a call to change the way university's reward faculty, however, there has been no change in the way faculty are tenured and promoted. It probably will take a world crisis for America's best and brightest to realize the potential for working with others globally in a range of fields to solve the world's greatest challenges.

What would it take to educate our college students today to feel comfortable in working with any group of individuals around the world on a project? Are our university students being prepared for this type of work? The answer today would be no for a majority of undergraduate students, however, in order to accomplish this, some skills for the future need to be entrenched into higher education institutions. As an example, a recent report from the Center for the Advancement of Engineering Education (CAEE) stated that undergraduate engineering education students reported a considerable increase in intellectual growth, but reported lower personal growth and fewer opportunities to study abroad than other college students (Atman et.al, 2010). 


\section{What skills are needed to succeed in the globalized world?}

In preparing for a global career, students in their undergraduate studies should try to acquire global competencies and multicultural skills. Included in the global competencies would be workable knowledge of global leadership skills which are essential to succeed in a globalized world. If you intend to be a global leader, you should know the answers to the following questions. These questions were provided by working professionals at the IBM Corporation:

- What skills are required in a global environment?

- What to do and what not to do when leading in a global environment?

- How to identify \& tackle problems in a global team?

- How to think outside the box and use innovative \& creative ideas in a global team?

- How to leverage the assets within a global team? (Gandhi, 2009)

IBM, described as world's top provider of computer products and services, defines six competencies that global leaders should possess when managing global teams:

- The ability to leverage global assets or managing global resources effectively and efficiently.

- The ability to serve distinct global markets and seek new client opportunities.

- The ability to address with the team; who has control to make decisions, how are risks, successes, and accountabilities shared within the team.

- The ability to build collaboration within your global team through traditional methods or new collaborative tools.

- The ability to understand and manage the different specialization in the team, utilize and componentized the skills as needed.

- The ability to identify the key skills in the global team and utilize them in such a way that you get the most value from the project (Gandhi, 2009).

Gandhi goes on to indicate global team barriers that can hamper a team's development, they are: cultural differences; differences in expertise levels; geographic time zones differences; trust issues; language and communication differences; and work style differences. These are all further explained below:

- Cultural differences - There are differences in countries, educational systems, religious backgrounds, environments, and cultures. Just in the cultural differences there are differences in individual verses collective orientation which come into play too. The best way to handle this is to build a cultural awareness, and acceptance in the team.

- Differences in expertise level - The differences in expertise in a team can lead to ego issues. This is a challenge for the leader because ego problems can cause distrust issues. It is the leader's role to understand the expertise of each of the team members.

- Geographic time zones differences - The lead must consider a common time but also take into consideration cultural considerations. Allow flexible work schedules to accommodate individuals. And if needed allow for a share the pain approach so that everyone suffers equally. Always clearly communicate the acceptable time range to host a meeting. Perhaps it is not necessary for all to participate in all the meetings, make sure the right people are included in the right meetings.

- Trust issues - Leaders must build the trust in the team. The leader should have at least one face to face meeting so that everyone can meet. Introduce a break the ice type scenario so that individuals can meet and learn about each other in a relaxed atmosphere before the team starts on the project. Clearly communicate team objectives, 
team responsibilities, team member accountabilities, project timelines, risks, etc to all team members. To build trust, communication is extremely important.

- Language and communication differences- English words have different meaning in different languages so this is an area that can be extremely difficult. The use of colloquials can be very complicated in conversations. Encourage clarifications, and use a lot of pauses in communications to make sure everyone to clear.

- Work style differences- Each member of the team will have different work styles and this will reflect their culture. Even a local team of individuals will have different work styles. As long as individuals can work independently and they are aware of the project deadline, goals, risks and accountability then they can still succeed (Gandhi, 2009).

Building collaborative teams in the university setting can be simulated to some extent. Some of the tools available today that can be used to accomplish this are: WIKIs; Chat Rooms, Forums, Discussion Boards, Lotus Notes; Instant Messaging; Video Chats or Web Video Conferences; and Virtual Workspace Tools. These tools can be used to connect with one member of the global team or have a whole global team meeting. They can also be used for informal get together or so called global team coffee breaks for non work related talk or to celebrate team events (i.e., team member birthday, etc.).

\section{Identify model collaborative international teams}

Today international corporations and industries are looking for individuals who can work in a global world. International organizations have offices all over the world or may work with other organizations in order to get innovative products or services to market at the fastest possible speed. These individuals will need to know how to work successfully in international, multicultural, and interdisciplinary teams. For example, most engineering institutions produce one-disciplined technically successful skilled engineers; however, they don't all produce engineers that are capable of working outside their discipline let alone working in a global world.

Engineering can be used as an example of one of these professions where industry has emphasized the need for more soft skills from the engineering graduate, who usually graduates with a multitude of technical skills in their related field of study and very little in the way of teamwork, communication, flexibility, multidisciplinary team work, leadership, and hardly any thoughts to multicultural and global awareness.

One example of teaching multidisciplinary team skills to engineering students was conducted in Europe with a group of six European university institutions from five European countries; Denmark, Czech Republic, Poland, Portugal, and The Netherlands. This group of universities working with an industry partner in Denmark developed a summer school for engineering students, which was specifically designed to include innovation, as well as the following:

- Team- oriented Activities- Students worked collaboratively in teams to develop and engineer a product.

- Multidisciplinary Approach- Teams were composed of students with different discipline backgrounds, but whose skills, knowledge, and experiences were important to achieve the project's goal.

- Multicultural Approach -Teams were composed of students from different countries.

- $\quad$ Problem-based Learning -Learning was centered on students, using open assignments with several solutions possible and professors served as tutors. 
- Intensive Schedule -Students worked solely on the project because of the short three week summer term.

- Industry-oriented - Summer school takes place in an industrial setting and the assignments given to the students are closely aligned with the industry requirements (Larsen et al., 2009).

The students, who participated in the multidisciplinary, multicultural project, summer school were pleased with the course. The industry partner was very impressed with the quality of the innovative ideas, the animations and the prototypes. The faculty involved planned to improve the technical analysis from industry partners and plan to add more multidisciplinary activities in cost and marketing analysis. The most valuable outcomes of the summer school was the new ideas, recruitment potential, and inspiration that the young students' received out of the experience. There was no doubt that it was a very successful summer school (Larsen, et al., 2009). Another model program named, International Networked Teams for Engineering Design (INTEnD) program involves Michigan State University (MSU) and the University of Texas Pan American is meeting the challenges of globalization by offering collaborative, multidisciplinary, and innovative engineering education programs. The research and education program was started in 1998 by a multidisciplinary team of educators from MSU and other engineering educators from a variety of universities around the world; Technical University Deft, University of Utrecht, Eindhoven University, Kaiserslautern University, Tsinghua University, Catholic University of Leuven, St. Petersburg Technical University, Carlos III University, and Monterrey Institute of Technology and Higher Education (ITESM) (Mariasingan et al, 2007).

In addition, the University of Michigan has also added an Engineering Global Leadership Program, Global Product Development Course, and a partnership with a Chinese university, Shanghai Jiao Tong University in order to prepare their engineering students for a global career. Other engineering school's such as Purdue University created a Global engineering program in 2005, which focuses on preparing students for a global world. The University of Wisconsin- Madison has a certificate in International Engineering (Mariasingan et al, 2007). All of these changes in engineering education show that the faculty and administration in these universities are at the forefront of educating a global workforce.

Brigham Young University received a National Science Foundation (NSF) grant to implement a global virtual team's course taught concurrently with an international capstone experience in an engineering school. This course provided students with an opportunity to be in a productive cross-cultural experience in an effective manner. This course was not meant to replace face to face interaction in different cultures (study abroad opportunities) but was meant to supplement students practice in international virtual teams and to successfully use their engineering skills. The global virtual team's course increased the understanding of other cultures (Zaugg et al, 2010).

\section{Discuss the importance of teaching globalization in higher education}

In 2010 a global study entitled Attributes of a Global Engineer was performed by the American Society for Engineering Education (ASEE) and the International Federation of Engineering Education Societies (IFEES) to determine the skills and experiences that today's engineering student need to develop in school and throughout their career to successfully compete in a global workplace. ASEE's Board of Directors established the ASEE Corporate Member 
Council (CMC) to convey the ideas and views of corporations to ASEE. With over 120 corporate and non-academic institutional members, the $\mathrm{CMC}^{\prime} \mathrm{s}$ mission is to foster, encourage, and cultivate the dialogue between industry and engineering educators. Its strategic goals are:

- Diversity in engineering education

- Enhancing the K-12 educational pipeline/future workforce

- Reforming engineering education

- Collaborating on engineering research and intellectual property

- Liaison with engineering, technology, and the Society

CMC has several Special Interest Groups (SIGs), which exist to share information and advance key priorities of the CMC. The International Engineering Education SIG is the CMC sponsor of the Attributes of a Global Engineer Survey Project.

The Attributes of a Global Engineer Survey Project grew out of an expressed need by CMC members to identify and validate specific knowledge, skills, abilities, and perspectives that would be required of an engineer living and working in an increasingly global context. Specifically, the goal was to refine a list of attributes that would be applicable to engineers regardless of specialty, location, or background.

The process began in early-2008, led by the International Engineering Education SIG, and involved CMC members developing a list of competencies derived from representative job descriptions, literature reviews, and other reports. This initial list was consolidated through a series of SIG meetings and events throughout 2008 and 2009; thus, here are the attributes that emerged through this process (Hundley et al, 2011):

- $\quad$ Engineering Science Fundamentals

- Mathematics (including statistics)

- Physical and Life Sciences

- Political and Socio-economic Sciences

- Information Technology - Digital Competency

- Engineering

- Understanding of Design and Product Processes

- Understanding of Product Life Cycle Development

- Effective Teamwork/Common Goals

- Possess a Multi-Disciplinary, Systems Perspective

- Maintain Focus with Multiple Project Assignments

- Context in which Engineering is practiced

- Economics/Finances of Projects

- Basic Supplier Management Principles

- Customer and Societal Emotions and Needs

- Cultures, Languages, and Business Norms

- Societal, Economic, and Environmental Impacts of Engineering Decisions

- An International/Global Perspective

- Communication

- Written (Memos, reports, email, letters, etc.)

- Verbal (Technical \& non-technical presentations plus an effective "elevator" speech)

- Foreign Language (Technically fluent in at least two languages acknowledging English is considered a key global language) 
- Graphic (Design drawings, charts \& graphs, presentation, and basic brochure design)

- Digital Competency

- Competent at Internet Collaboration and Communication Tools (Web-based meeting tools, team rooms, teleconferencing; file sharing, E-mail, etc.)

- $\quad$ Listening

- Teamwork

- Active and Effective Participation in Team Efforts

- A Willingness to Respect the Opinions of Others and Support Team Decisions

- Leadership

- An Acceptable Personal Image and a Positive Personal Attitude

- Treating People with Fairness, Trust, and Respect

- $\quad$ Respect for Diversity

- Courtesy and Respect

- An Eagerness to Help Others

- Flexibility

- Self-Confidence to Adapt to Rapid/Continuous/Major Change

- Thinking Both Critically and Creatively - Independently and Cooperatively

- Curiosity and Desire to Learn - For Life (Show initiative, Inquire \& Learn)

- Seeking Advice and Forming Daily Questions to Discover New Insights.

- Commitment to Quality, Timeliness, and Continuous Improvement

- Understanding Basic Project and Risk Management and Continuous Improvement Concepts (like LEAN+)

- $\quad$ Ethical Standards and Professionalism

- Operate in Accordance With Acceptable Business, Societal, and Professional Norms

- Maintain the Highest Level of Integrity, Ethical Behavior, and Professional Competence

- Understand and Applies Good Personal Judgment

At the ASEE Annual Conference in 2010, SIG stakeholders attempted to translate the attributes into specific competencies that could be identified by levels of importance and proficiency at certain intervals of an individual's education and professional development. The initial list totaled 48; however, through in-person meetings at the Conference, and through bi-weekly telephone conference calls and other electronic communication, the list was ultimately synthesized and consolidated. After further review and validation from CMC members, a total of 20 competencies associated with the attributes of a global engineer emerged (Hundley et al., 2011). These are:

1. Demonstrates an understanding of engineering, science, and mathematics fundamentals

2. Demonstrates an understanding of political, social, and economic perspectives

3. Demonstrates an understanding of information technology, digital competency, and information literacy

4. Demonstrates an understanding of stages/phases of product lifecycle (design, prototyping, testing, production, distribution channels, supplier management, etc.)

5. Demonstrates an understanding of project planning, management, and the impacts of projects on various stakeholder groups (project team members, project sponsor, project client, end-users, etc.) 
6. Demonstrates an understanding of the ethical and business norms and applies norms effectively in a given context (organization, industry, country, etc.)

7. Communicates effectively in a variety of different ways, methods, and media (written, verbal/oral, graphic, listening, electronically, etc.)

8. Communicates effectively to both technical and non-technical audiences

9. Possesses an international/global perspective

10. Possesses fluency in at least two languages

11. Possesses the ability to think both critically and creatively

12. Possesses the ability to think both individually and cooperatively

13. Functions effectively on a team (understands team goals, contributes effectively to team work, supports team decisions, respects team members, etc.)

14. Maintains a positive self-image and possesses positive self-confidence

15. Maintains a high-level of professional competence

16. Embraces a commitment to quality principles/standards and continuous improvement

17. Embraces an interdisciplinary/multidisciplinary perspective

18. Applies personal and professional judgment in effectively making decisions and managing risks

19. Mentors or helps others accomplish goals/tasks

20. Shows initiative and demonstrates a willingness to learn

The Attributes of a Global Engineer study indicated that a majority of the respondents, $52.5 \%$, indicated that it was important, that an engineer functions effectively upon graduation from Tertiary/College/University on a team (understands team goals, contributes effectively to team work, supports team decisions, respects team members). As well, the same study indicated that, $48.4 \%$, indicated that it was important, that engineers possess an international/global perspective upon graduation from Tertiary/College/University. In addition, the study indicates that a majority, 53.8\%, indicated that it was important, that an engineer embraces an interdisciplinary/multidisciplinary perspective. This international study indicates that it is important for engineers to develop global skills while they attend Tertiary/College/University (Hundley et al, 2011).

A study by the National Academy of Engineering, The Engineer of 2020, calls for future engineers in the U.S to have complex social, global and professional skills to be successful in the future. There are a number of underlying guiding principles that lead the authors of this study to their conclusions, they are: (1) the continued pace of accelerating technological innovation; (2) the fact that technology deployed will continue to be intensely globally interconnected; (3)those affected or involved with technology will be increasingly diverse and multidisciplinary; (4) technological innovation will be shaped and affected by social, cultural, political, and economic forces; and (5) technology in everyday lives will be more seemingly transparent and more significant than it is today. Given those underlying principles the authors of the study suggested strongly that engineers of the future should have the following team skills in a global context: collaborate in a multidisciplinary and multicultural team of experts across multiple fields; have excellent communication skills with both technical and non-technical individuals; be able to communicate with technology, have an understanding for complex global markets and social context, be flexible, be receptiveness to change, and have mutual respect for everyone (Committee on the Engineer of 2020, 2004). In the past, the engineering profession use to respond as technology and society changes, but today technology is changing very rapidly and society is continually changing. We need to know how to work in a faster more global society. 


\section{Discuss the best practices in teaching globalization}

To best teach globalization, students need to experience it, so it goes without saying that university students must take advantage of studying abroad, international internships, or research opportunities abroad. Another best practice opportunity for students is to be proficient in at least one foreign language, while it is common to be proficient in several languages in Europe this is not widely practiced in the U.S. During a graduate program, students should take advantages of enrolling in foreign universities and pursuing a dual degree, especially one that has an agreement with the university you are attending. Faculty should create sustainable networks with a foreign university in education or research in order to provide their students with these options. The institution should have a formal process or framework for globalization. It might include a discussion on how will the curriculum be restructured to include globalization, what teaching methods will be best used, and/or should international interdisciplinary research centers be established. Global competencies need to be a part of every undergraduate's education and all barriers should be removed so that more work can be done on global research (Widdig \& Lohmann, 2007).

The Wharton School of Business is changing its curriculum to better prepare its graduates for a fast changing global business environment. Changes to their curriculum include several focused short term courses in the U.K., India, Brazil, China, Israel and South Africa. For example, the course in Brazil is about the environment, the one in Israel is about technology, etc. Wharton has also added courses to their curriculum in global finance, management and an increased focus in soft skills like writing, leadership and multicultural understanding (Korn, 2011). These types of curriculum changes are happening in other elite business schools as well.

In Finland, globalization is integrated in the curriculum to promote internationalization of higher education. However, specialization and depth is more important in engineering education in the United States than internationalization. In Finland, internationalization is defined through three areas: mobility, multiculturalism, and networking. The key areas for internationalization in the engineering education in Finland are through:

- $\quad$ student, teacher, and researcher mobility;

- international R\&D projects;

- development of joint and double degrees with other institutions in other countries;

- increase in foreign students and researchers in Finland;

- measures in supporting the integration of foreign students and personnel in Finland;

- development of the exportation competencies;

- enhanced study opportunities for non-native speakers and those with immigrant backgrounds; and

- more efficient use of the international organizations and cooperation arrangements (Tossavainen, 2009, p.528).

All of these key areas cover mobility, multiculturalism and networking.

Another excellent example of best practices of readying students to work in the global world has been practiced in The Georgia Institute of Technology since the late 1990's when Georgia Tech's President, Dr. G. Wayne Clough, took office in 1994. President Clough realized fast that there were a number of talented students on campus who were multi-dimensional. These students were good in music, sports or some other area and in addition these students also were interested in engineering. These students were not the 
best engineering students, these students were able to communicate, they were more socialized, they asked for help when needed, they thought horizontally, and most of all these students were able to tie things together from different disciplines and fields. These students made great engineering students because of these other qualities. Since that finding in the late 1990's, Georgia Institute of Technology started targeting a unique group of freshmen, till $50 \%$ of the entering freshman in engineering played musical instruments, or participated in a musical group. This was so prevalent that President Clough had to build more recital and concert areas on campus. President G. Wayne Clough created a different kind of graduate. The students that graduate from the Georgia Institute of Technology in engineering are adaptable and can think across the disciplines and therefore are ready for a global flat world (Freidman, 2007).

Thomas Friedman said in his book, The World is Flat, that the one ability students should have when leaving college is the ability to, "learn how to learn - and to constantly absorb, and teach yourself, new ways of doing old things or new ways of doing new things" (2007, pg 309). Friedman goes on to say that what you know today will soon be out of date. Thus, university students need to be aware that lifelong learning is a skill that they will need to incorporate throughout their life whether it is exploring globalization or broader aspects of a specific discipline.

Recently, there has been a call in engineering education to supplement the current curriculum with globalization, team work and multi-culture learning. However, there is also a call to bring back the excitement that an engineering profession use to enjoy, especially in a world where society needs sustainable supplies of energy, water, food, and healthcare with trends toward globalization (Turner, 2010). Turner goes on to say, "The curriculum must incorporate active, engaging and relevant learning, teaching and assessment strategies to develop, self-aware, well-motivated, enterprising and independent learners" (2010, pg 36.).

Some university students learn the lessons of globalization by studying internationally. Some 3 million international students study abroad. Meaning they study at universities outside their home countries. Newly created or expanded universities in China, India, and Saudi Arabia are competing with the same students, faculty and research pre-eminence of that of Harvard and Oxford. A good example of this would be the President of King Abdullah University Science and Technology (KAUST), a brand new graduate school in Saudi Arabia. The President, who is originally from Singapore but who had a global trotting career path through Canada, United States and back to Singapore before taking the President's position in Saudi Arabia. The renowned international business school INSEAD, has campuses, in France, Singapore, Israel, and Abu Dhabi. Students study on several campuses. (Wildavsky, 2010).

Finally, there are some pragmatic strategies to facilitate, encourage, and sustain globaloriented teaching in higher education-approaches that are adaptable to a variety of disciplines and institutional contexts. These include:

- Increasing the size of the international student body population

- Increasing the size of foreign-born faculty members

- Developing or expanding partnerships with international institutions

- Providing for robust study abroad experiences of varying lengths and contexts

- Engaging students in classroom, co-curricular, and other educational activities that heighten their awareness of internationalization

- Fostering service learning, undergraduate research, and experiential education that includes an international component 
- Leveraging the partnerships of other stakeholders (e.g., alumni, business/industry organizations, professional associations and societies, community members) to provide a platform for students to participate in international learning opportunities.

\section{Conclusion}

By 2025, internationalization will have sharpened the hierarchy in world higher education, with a handful of university "transnational corporations" in the highest tier alongside private firms and local community college-style institutions in the lowest. This is one of the predictions made by Felix Maringe, Senior Lecturer in education at the University of Southhampton and Nick Foskett, Vice Chancellor of Keele University in a book they edited titled, Globalization and Internationalization in Higher Education. So while there is a concern of just how to teach globalization in higher education, there is also a big push for universities to go global (Morgan, 2010). Vice Chancellor Foskett says that the key theme of the book is the failure of universities to understand higher education internationalization in the context of the globalization of the world economy, rather than as a simple recruitment of international students. The book indicates that internationalization will be innate for universities at the top of the tier through crosscultural programs, overseas campuses or distance learning (Morgan, 2010). This is only one small solution for globalizing students.

In the world today, there are over 1 billion people who don't have adequate supplies of clean water, countless who don't have access to medical care, millions who live without enough to eat. We live in a world that is more interconnected and more vulnerable than ever before. Infectious diseases can be transmitted easily across countries because we are so mobile. The grand challenges, no matter what group they are hailed from, in this century are huge. The young people, who are in universities and colleges, are the ones that can work towards solving these grand challenges, but it is the responsibility of those teaching these students to make sure they are equipped with right set of skills to make sure they are able to work with multicultural multidisciplinary teams to solve the problems that face the world. In pursing the grand challenges of the century, the world is much smaller and more inclusive and more connected. The challenges of the century are not that of isolated locales but of the planet as a whole. Therefore, globalization of education must be a necessary part of higher education. Business and engineering schools alike in the United States have added or are considering globalization as an important addition to a student's higher education package. Globalization is already an important part of European education. Globalization is not a passing phenomenon. It is here to stay. Universities and colleges throughout the world need to recognize that every student needs to have global skills.

\section{References}

Atman, C.J., Sheppard, S.D., Turns, J., Adams, R. S., Fleming, L.N., Stevens, R. Streveler, R.A., Smith, K.A., Miller, R. L., Leifer, L.J., Yasuhara, K., \& Lund, D. (2010). Enabling Engineering Student Success: The Final Report for the Center for the Advancement of Engineering Education. Morgan \&Claypool Publishers. 
Constable, G., \& Somerville, B. (2003). A Century of Innovation: Twenty Engineering Achievements That Transformed Our Lives. John Henry Press, Washington, D.C.

Committee on the Engineer of 2020. (2004). The Engineer of 2020:Visions of Engineering in the New Century. The National Academies Press. Washington, D.C.

Freidman, T. (2007). The World is Flat. Picadorusa. New York, NY.

Gandhi, L. (2009). Breaking the Ice: Cutting through Geographic, Cultural, and Time Zone Barriers to Effectively Lead in a Global Environment. American Society for Engineering Education, AC 2009-694.

Glenn, J. C, Gordon, T.J. \& Florescu, E. (2010). 2010 State of the Future (The Millennium Project), ISBN: 978-0-9818941-3-3.

Grand Challenges for Engineering Committee. (2008). Grand Challenges for Engineering. National Academy of Engineering. Published by the National Academies of Engineering.

Highfield, R., \& Lawton, G. (April 14, 2010). Global Challenges: What the World's Scientist Say, NewScientist Magazine. Magazine Issue 2756.

Hundley, S., Brown, L., Jacob, A., Fox, P., Didon, K., Sayre, D., \& Hoyer, H (2011). Attributes of a Global Engineer: Results of a Work-in-Progress International Survey. American Society for Engineering Education. AC 2011-205.

Korn, M. (February 3, 2011). Business Education: As World Turns, Wharton Adapts. Wall Street Journal (Eastern Edition). New York, N.Y. pg.9.

Larsen, P.G., Fernadez, J.M., Habel, J.M., Lehrskov, H., Voc, R.J.C., Wallington, O. \& Zidek, J. (2009). A multidisciplinary engineering summer school in an industrial setting. European Journal of Engineering Education. Vol.34, No.6, December 2009, 511-526.

Mariasingam, M., Couter, S., Smith, T., \& Moses, G., (2007). Globalization and Engineering Education for 2020. American Society for Engineering Education. AC 2007-2962.

Morgan, J. (September 30, 2010). Face of higher education to change forever in 15 years. The Times Higher Education Supplement. TSL Education Limited. Issue 1967. pg 12.

Sterling, B. (July 17, 2010). Futurist ponder planet, avoid despairing, In: Beyond The Beyond. Wired. Com. Just another WordPress Weblog, Date of access, March 10, 2011, Available from:

(http://www.wired.com/beyond_the_beyond/2010/07/futurists-ponderplanet-avoid-despairing/)

Tossavainen, P.J. (2009). Institutionalising internationalization strategies in engineering education. European Journal of Engineering Education. Vol. 34, No.6, December 2009, 527-543.

Turner, J.D. (2010). Putting the world back in working order. The Times Higher Education Supplement. London. April 29, 2010, Issue 1945: pg 36.

Wildavsky, B. (2010). The Great Brain Race. Princeton University Press., Princeton, New Jersey. ISBN 978-0-691-14689-8. 
Widdig, B., \& Lohmann, J. (2007). Educating Engineers for the Global Workforce. American Society for Engineering Education. AC 2007-854.

Zaugg, H., Davies, R., Parkinson, A. R., Magleby, S.P., Jensen, G., \& Ball, A.B. (2010). American Society for Engineering Education. AC 2011-291. 


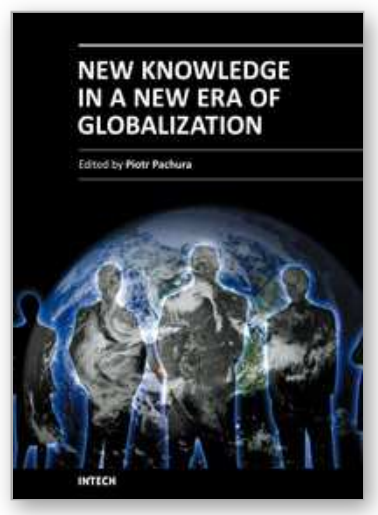

\author{
New Knowledge in a New Era of Globalization \\ Edited by Prof. Piotr Pachura
}

ISBN 978-953-307-501-3

Hard cover, 354 pages

Publisher InTech

Published online 01, August, 2011

Published in print edition August, 2011

To better understand the contemporary world, the world of innovation and technology, science should try to synthesize and assimilate social science in the development of our civilization. Does the new era require new knowledge? Does the age of globalization demand new education, new human attitudes? This books tries to clarify these questions. The book New Knowledge in a New Era of Globalization consists of 16 chapters divided into three sections: Globalization and Education; Globalization and Human Being; Globalization and Space. The Authors of respective chapters represent a great diversity of disciplines and methodological approaches as well as a variety of academic culture. This book is a valuable contribution and it will certainly be appreciated by a global community of scholars.

\title{
How to reference
}

In order to correctly reference this scholarly work, feel free to copy and paste the following:

Patricia Fox and Stephen Hundley (2011). The Importance of Globalization in Higher Education, New Knowledge in a New Era of Globalization, Prof. Piotr Pachura (Ed.), ISBN: 978-953-307-501-3, InTech, Available from: http://www.intechopen.com/books/new-knowledge-in-a-new-era-of-globalization/theimportance-of-globalization-in-higher-education

\section{INTECH}

open science | open minds

\author{
InTech Europe \\ University Campus STeP Ri \\ Slavka Krautzeka 83/A \\ 51000 Rijeka, Croatia \\ Phone: +385 (51) 770447 \\ Fax: +385 (51) 686166 \\ www.intechopen.com
}

\author{
InTech China \\ Unit 405, Office Block, Hotel Equatorial Shanghai \\ No.65, Yan An Road (West), Shanghai, 200040, China \\ 中国上海市延安西路65号上海国际贵都大饭店办公楼405单元 \\ Phone: +86-21-62489820 \\ Fax: +86-21-62489821
}


(C) 2011 The Author(s). Licensee IntechOpen. This chapter is distributed under the terms of the Creative Commons Attribution-NonCommercialShareAlike-3.0 License, which permits use, distribution and reproduction for non-commercial purposes, provided the original is properly cited and derivative works building on this content are distributed under the same license. 